\title{
Pathways to increase consumer trust in meat as a safe and wholesome food
}

\author{
Xavier Gellynck *, Wim Verbeke, Bert Vermeire \\ Ghent University, Faculty of Bioscience Engineering, Department of Agricultural Economics, Coupure links 653, 9000 Gent, Belgium
}

Received 13 March 2006; received in revised form 19 April 2006; accepted 24 April 2006

\begin{abstract}
This paper focuses on the effect of information about meat safety and wholesomeness on consumer trust based on several studies with data collected in Belgium. The research is grounded in the observation that despite the abundant rise of information through labelling, traceability systems and quality assurance schemes, the effect on consumer trust in meat as a safe and wholesome product is only limited. The overload and complexity of information on food products results in misunderstanding and misinterpretation. Functional traceability attributes such as organisational efficiency and chain monitoring are considered to be highly important but not as a basis for market segmentation. However, process traceability attributes such as origin and production method are of interest for particular market segments as a response to meat quality concerns. Quality assurance schemes and associated labels have a poor impact on consumers' perception. It is argued that the high interest of retailers in such schemes is driven by procurement management efficiency rather than safety or overall quality. Future research could concentrate on the distribution of costs and benefits associated with meat quality initiatives among the chain participants.
\end{abstract}

(C) 2006 Elsevier Ltd. All rights reserved.

Keywords: Food safety; Information; Traceability; Quality assurance schemes

"Trust is good, but control is better"

Vladimir Lenin

\section{Introduction and research question}

Consumer trust and food safety have become a central issue in the food chain (Grunert, 2005; Röhr, Lüddecke, Drusch, Müller, \& Alvensleben, 2005; Verbeke, 2005). During the past two decades, food safety crises such as the mad cow disease throughout Europe, the dioxin crisis in Belgium, and outbreaks of foot-and-mouth disease in several countries led consumers to rethink their attitudes to and behaviour towards meat consumption (Gellynck \& Verbeke, 2001; Latouche, Rainelli, \& Vermersch,

\footnotetext{
* Corresponding author. Tel.: +329 26459 23; fax: +32 92646246.

E-mail address: Xavier.Gellynck@UGent.be (X. Gellynck).
}

1998). Due to the increasing health and safety consciousness, both industry and the public authorities have developed quality and safety assurance systems (Hobbs, Bailey, Dickinson, \& Haghiri, 2005; Schwägele, 2005; Theuvsen, 2003). Further, the crises induced a sharp and immediate drop in the demand for meat products, followed by a slow and often incomplete recovery (Böcker \& Hanf, 2000; Verbeke, 2001).

Within the modern meat chain, consumers occupy a crucial position being situated at the end of the chain as the end user as well as at the start of the chain as inspiration for a consumer-driven or market oriented chain organisation (Gellynck, Verbeke, \& Viaene, 2004). The latter position makes consumer demand for safe and wholesome food in general and meat in particular the greatest driving force for the introduction of a variety of information systems such as branding, traceability and quality assurance schemes (Gellynck \& Verbeke, 2001; Leat, Marr, \& Ritchie, 1998). 
Trust is considered to be a precondition for exchange (Fischer, Gonzalez, Henchion, \& Leat, 2006). In the context of the food system, trust is strongly related to risk. Trust differs from confidence in the sense that trust recognises the presence of a risk (Luhmann, 1988). In the case of confidence, no risk is perceived. At the same time, the amount of trust in food can be defined as being opposed to the amount of food risks (Grunert, 2005). Moreover, the relation between food risk and trust is inversely proportional as people who have higher levels of trust in the food system will be less concerned with risks and vice versa (Knight \& Warland, 2005). The dichotomy between trust and risk is related to information provision, as trust can be understood as the individual and subjective response to the objective and rather abstract notion of risk (Berg, 2004). In this way, communication strategies have to take into account the transformation of objective risk into subjective response in terms of trust. The relations between objectivity and subjectivity can be demonstrated by contrasting the level of provision of quality and safety on the one hand and the level of consumer perception on the other, two levels of research about safety distinguished by Grunert (2005). On the provision level, there is a good possibility of objectively assessing safety.

Recent developments in the field of labelling, traceability and quality assurance schemes offer vast streams of information accessible to the consumer. With respect to consumer perception, however, this is not that straightforward. The objective information is not automatically reflected by the perception, because the latter not only depends upon the amount of information released, but also upon the emotional content of the message (Rosa, Sanchez, $\&$ Barrena, 2006). Moreover, the objective content of the message will be perceived differently by different consumer segments (Bernués, Olaizola, \& Corcoran, 2003; Frewer, Fischer, Scholderer, \& Verbeke, 2005; Miles \& Frewer, 2001; Verbeke \& Vackier, 2004).

Within the context of our paper, three aspects related to information are distinguished: consumer interest in traceability as a response to quality concerns, information on meat labels, and the role of quality assurance schemes. The objective of the paper is to verify whether these three aspects of information manage to generate additional trust for consumers in meat safety and wholesomeness. This paper is structured as follows. Section 2 briefly discusses the role of information in relation to trust and reducing uncertainty. Section 3 provides an overview of the research methodology used to answer the research questions. Section 4 illustrates that information additional to the legal requirements of traceability may increase consumers' perception of meat as a safe and wholesome product. Section 5 argues that consumers' willpower and capacity to handle product information is limited and explores how traceability information on meat labels can best be provided to consumers. Section 6 presents a critical view about the role of food quality assurance schemes at consumer level. Finally, conclusions and a future research agenda are presented.

\section{Trust and information}

Consumer trust in food products does not necessarily reflect the objective information that is communicated. The problem is depicted in Fig. 1. One of the main goals of food safety measures is to increase consumer trust in food and reduce uncertainty, and therefore information about meat quality and safety is provided to the consumer. Throughout the EU, both public and private initiatives such as new regulations and the introduction of voluntary quality assurance schemes are established to guarantee consumers that food is safe and wholesome. However, consumer trust will not be achieved unless there is increased effort to communicate risk (Frewer et al., 2005). To achieve this, the removal of information asymmetry through the provision of more information is often believed to be the most logic solution (Kola \& Latvala, 2003; Yee, Yeung, $\&$ Morris, 2005). However, effective communication has to take into account differences among consumers' concerns. In this respect, authors distinguish differences in terms of purchasing motives and labelling preferences (Bernués et al., 2003) or risk perception (Frewer et al., 2005). Further, consumer concerns differ according to the type of food hazard (Miles and Frewer, 2001). This complexity in providing information is due to the fact that consumers are interested in very different properties of the food product (Theuvsen, 2003).

Information from today's agriculture and food markets has to surpass several hurdles in order to be effective at the consumer level, e.g. building or strengthening consumer trust. A first hurdle relates to the availability and accessibility of information. Limited availability and accessability to information yields potential market failures in the sense that consumers are hampered in making choices in line with their preferences (Caswell \& Mojduszka, 1996; Teisl \& Roe, 1998). However, even when information is made sufficiently available and accessible to consumers, only a limited amount of this information is attended to, i.e. attracting consumers' attention in an environment characterised by information overload and raising interest for being processing. The explanation lies in the limited human cognitive capacity and willpower to process information on the one hand, and in high opportunity cost of processing information as compared to the expected marginal benefit of devoting time and effort to information processing on the other. Furthermore, there is a real potential danger of information overload. Increasing the amount of informa-

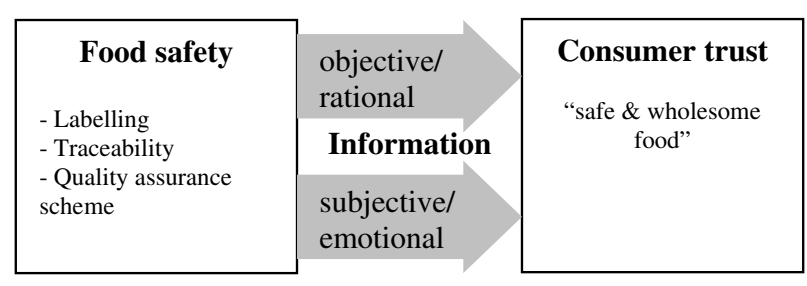

Fig. 1. Research question. 
tion, for instance on the product label, may overload the label or package, and make a given and desired amount of information harder to extract, or simply cause individuals without time or ability to process information to ignore it, hence yielding excess costs (Salaün \& Flores, 2001). It may also yield boredom and impatience, as well as loss of confidence from non-understanding.

Food labelling is an increasingly important route for delivering messages about the safety and wholesomeness of food to consumers. It has long been understood, however, that the presupposition that consumers want, will acquire and, having acquired, will adequately understand and use the information supplied on labels is invalid (Jacoby, Chestnut, \& Silberman, 1977). Furthermore, labelling information is often inaccessible and useless to consumers (Hobbs et al., 2005; Salaün \& Flores, 2001). It has yet been shown that consumers often misunderstand or misinterpret information, e.g. relating to quality or origin, which yields the formation of quality expectations that may not be confirmed by actual product performance upon consumption (Grunert, 2005). As a result, a particular challenge pertains to determining the optimum level of simplicity versus detail for any information to be provided, which is likely to differ depending on the individual and the product at hand.

\section{Materials and methods}

Empirical data from three consumer studies will be discussed to strengthen the argument of this paper. To assess consumer perception of traceability in the meat supply chain, the research framework presented in Fig. 2 is used (Gellynck \& Verbeke, 2001). The meat chain from producer to consumer constitutes the core of the framework. Tracking meat products within this chain focuses on two types of attributes, namely functional attributes such as

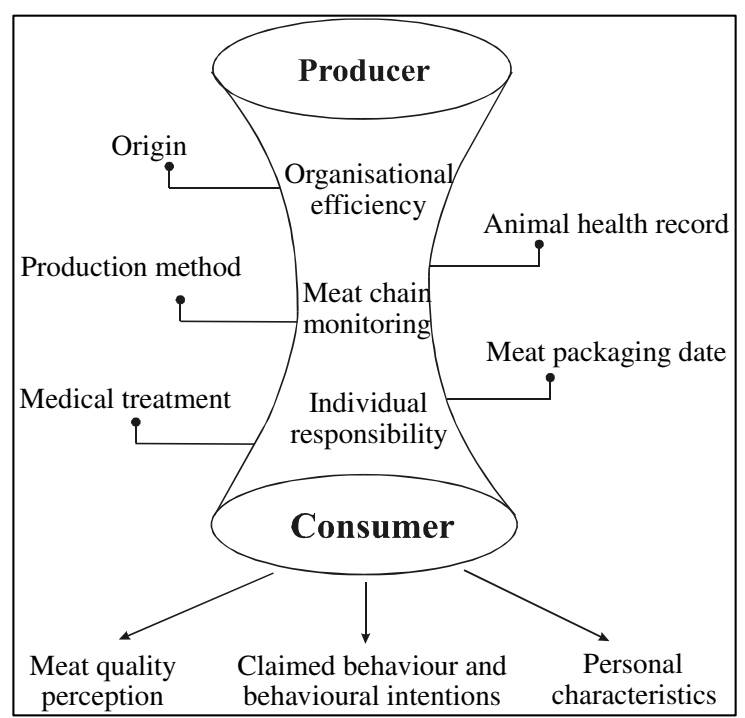

Fig. 2. Framework for research into consumer perception of traceability. organisational efficiency and meat chain monitoring on the one hand, and process attributes such as origin and production method on the other. Functional attributes are linked with the intrinsic opportunities of a traceability system, while the process attributes deal with characteristics of the production process along which the tracking is organised. The tracking serves as a kind of peg for potential consumer benefits.

Two consumer studies used cross-sectional consumer data collected from a sample of 170 meat consumers in Belgium in June 2001 and from a sample of 155 meat consumers in November 2004. Respondents were selected based on convenience sampling, with the restriction that they were the main person responsible for buying meat in the household, which resulted in a gender distribution with twothirds of female respondents. ${ }^{1}$ Findings from these studies are presented in Section 4.

Consumer interest in meat label information and traceability was further explored through a third consumer survey, performed in November 2005 in Belgium. Respondents were also selected using convenience sampling, but no restriction for being main shoppers was applied. The sample $(n=127)$ included $49.6 \%$ males and $50.4 \%$ females with age ranging from 16 to 79 years (mean age $=38.13$ years), of whom $56.7 \%$ were higher educated. First, respondents were asked about their use and importance attached to 10 meat label information cues (Fig. 3) on 5-point interval scales. Second, and after presenting a short description of what traceability means, respondent's awareness about the concept of traceability was assessed. Third, interest in different levels of traceability was measured through presenting statements about how information should preferably be made available using 5-point Likert scales. Fourth, respondent's opinions about who should possess detailed traceability information relating to place of birth, place of production, place of slaughter, place of processing and country of origin was measured on 5-point interval scales. Finally, respondents were shown four meat labels with different degrees of traceability information and probed about their preferred label. These labels were existing meat labels, including all mandatory information about price, weight, expiry date and meat type, though

\footnotetext{
${ }^{1}$ Methodological details related to the sampling procedure, sample characteristics and content of the questionnaire from the 2001 to 2004 surveys are provided in Gellynck and Verbeke (2001) and Gellynck et al. (2005). Readers are respectfully referred to the original publications. Details from the 2005 survey have not been provided elsewhere, therefore more detail with respect to this third consumer survey is included here. In each of the three studies, participants were selected using non-probability convenience sampling and samples were not statistically representative for the population. As a result, findings are to be interpreted as applicable to the samples at hand, whereas generalisation to the overall population is rather speculative. It should be noted that the 2001 and 2004 surveys included only people responsible for meat purchasing, whereas this restriction was not applied to the 2005 sample. This has no major implications since the findings from the first two studies are not compared in any way with those obtained from 2005 .
} 
with manipulated traceability information (Table 4). Findings from this study are presented in Section 5.

\section{Potential of traceability to increase consumer trust in meat}

\subsection{Meat quality perception}

A hierarchical cluster analysis (Ward's method squared Euclidean distance), followed by a $k$-means clustering on the perception of quality of fresh meat now compared with 5 years ago, resulted in a three-cluster solutions in 2001 and a four-cluster solutions in 2004 (Table 1). ${ }^{2}$ Quality perception is assessed using six fresh meat attributes, based on a 7-point semantic differential scale ranging from -3 to $+3 .{ }^{3}$ Fresh meat includes beef, pork, poultry and mixtures such as hamburgers and brochettes. Oneway ANOVA was carried out to illustrate the differences in quality perception between the clusters or consumer segments. The clusters are labelled based on an interpretation of their patterns of mean perception scores: enthusiasts, cautious and pessimists. In 2004, a new cluster can be identified and labelled as greens.

The total sample scores above the middle scale position of the semantic differential for the attributes safety, healthiness, animal welfare and environmental friendliness, whereas there are negative average scores for taste and price in 2001. The negative score for taste turns into a positive one in 2004. All attributes except price obtain a better score in 2004. Compared with 2001, there is a clear increase in overall meat quality perception which is translated into the enthusiasts becoming the most important segment with $34.4 \%$ of the respondents. The greens are a new segment representing $20.5 \%$ of the respondents and can be characterised as being positive related to safety and health, but negative towards the other attributes. The extremely low score for the environment is most striking.

\subsection{Consumer perception of traceability in the meat chain}

The perception of traceability of fresh meat is determined through the evaluation of eight statements on a 7point scale (Table 2). Consumers were asked to express the degree of importance they attach to possible attributes of traceability systems in the meat chain (see research framework). The functional attributes obtain the highest scores in the overall sample. Most importance is attached to 'individual responsibility' and 'meat chain monitoring'. Organising the chain in a more efficient way is somewhat less important, but still more important than most of the process attributes. All the functional attributes score significantly higher than the process attributes in the $t$-test for

\footnotetext{
${ }^{2}$ For more details about cluster analysis techniques see Malhotra (1999).

${ }^{3}$ A semantic differential scale is 7-point scale with end points being associated with bipolar labels indicating a semantic meaning.
}

paired comparison of means, except for 'meat packaging date'. This statement was assumed to be somewhat misleading, consumers confusing 'eat-by date' for 'meat packaging date'.

The importance consumers attach to the functional attributes does not differ significantly between segments. It can be concluded that organising traceability and related marketing efforts around the functional attributes cannot be considered an efficient instrument for changing perceptions of meat quality, since it does not address concerns about safety, healthiness, environment and animal friendliness. It also shows that organising traceability based on functional attributes will not meet consumer concerns or build consumer trust, as the retail sector often pretends.

Contrary to the functional attributes, most of the process attribute perceptions differ significantly between the segments. The scores given by the pessimists and the greens are systematically higher than those of the other two segments in 2004, which shows that focusing on information about additional process attributes through traceability could at least meet the meat quality concerns of these consumers. However, it is important to remember that the pessimists and the greens constitute only a limited part of the sample $(25 \%$ in 2001 and, respectively, $16 \%$ and $20 \%$ in 2004). It is therefore debatable whether it would be worthwhile organising such a traceability system (including opportunities for consumers to personally check process attributes) for the entire meat chain, though individual chain participants or private initiatives might find it useful to address the specific concerns of the market segments we call pessimists and greens.

\subsection{Consumer perception of the urgency of introducing traceability systems}

The questionnaire also focused on the perceived urgency of introducing a traceability system for the different meat types (Table 3 ). The system to be introduced was defined as one with the attributes considered important by the respondent. Consequently, respondents were asked to express the degree of urgency of introduction on a 7-point scale, ranging from 'not at all urgent' to 'extremely urgent'. The perceived need for a traceability system remains the highest in the case of meat mixtures compared with 2001. The differences in urgency between beef and poultry as well as between pork and poultry are not statistically significant. The top score for meat mixtures can be explained by the fact that evaluating mixture quality is perceived as more difficult than for the other meat types. Moreover, the risk of abuse is the highest in the case of mixtures.

Table 3 shows differences in the perceived urgency of introducing traceability between the identified consumer segments. Pessimists express the strongest need for traceability systems, which for all meat types is more urgent than for the other segments, both in 2001 and 2004. This means that consumers who are more concerned about meat quality and eat meat less frequently indicate a more urgent need for 
Table 1

Present perception of meat quality compared with five years ago, average attribute ratings on semantic differential from -3 to $+3(n=160$ in $2001, n=151$ in 2004)

\begin{tabular}{|c|c|c|c|c|c|c|c|c|c|}
\hline \multirow[t]{3}{*}{ Attribute } & \multicolumn{2}{|c|}{ Enthusiasts } & \multicolumn{2}{|c|}{ Cautious } & \multicolumn{2}{|c|}{ Pessimists } & \multirow{2}{*}{$\frac{\text { Greens }}{2004}$} & \multicolumn{2}{|l|}{ Total } \\
\hline & 2001 & 2004 & 2001 & 2004 & 2001 & 2004 & & 2001 & 2004 \\
\hline & $n=50$ & $n=52$ & $n=66$ & $n=43$ & $n=44$ & $n=25$ & $n=31$ & $n=160$ & $n=151$ \\
\hline Unsafe-safe & $1.94^{\mathrm{a}}$ & $1.96^{\mathrm{a}}$ & $0.97^{\mathrm{b}}$ & $1.00^{\mathrm{b}}$ & $-0.95^{\mathrm{c}}$ & $-1.08^{\mathrm{c}}$ & $0.81^{\mathrm{b}}$ & 0.74 & 0.98 \\
\hline Unhealthy-healthy & $1.70^{\mathrm{a}}$ & $1.37^{\mathrm{a}}$ & $0.30^{\mathrm{b}}$ & $0.40^{\mathrm{b}}$ & $-1.09^{\mathrm{c}}$ & $-1.36^{\mathrm{c}}$ & $0.52^{\mathrm{b}}$ & 0.35 & 0.50 \\
\hline Not animal friendly-animal friendly & $1.40^{\mathrm{a}}$ & $1.27^{\mathrm{a}}$ & $0.91^{\mathrm{b}}$ & $0 . .37^{\mathrm{b}}$ & $-0.70^{\mathrm{c}}$ & $-0.60^{\mathrm{c}}$ & $-0.68^{\mathrm{c}}$ & 0.28 & 0.32 \\
\hline Not environment friendly-environment friendly & $1.52^{\mathrm{a}}$ & $1.50^{\mathrm{a}}$ & $0.18^{\mathrm{b}}$ & $0.67^{\mathrm{b}}$ & $-0.34^{\mathrm{c}}$ & $-0.56^{\text {c.d }}$ & $-0.87^{\mathrm{d}}$ & 0.46 & 0.46 \\
\hline Tasteless-tasty & $0.40^{\mathrm{a}}$ & $1.04^{\mathrm{a}}$ & $-0.17^{\mathrm{b}}$ & $0.14^{\mathrm{b}, \mathrm{d}}$ & $-0.70^{\mathrm{c}}$ & $-0.92^{\mathrm{c}}$ & $-0.06^{\mathrm{d}}$ & $-0.14^{*}$ & $0.25^{*}$ \\
\hline Expensive-cheap & $-1.30^{\mathrm{a}}$ & $-1.62^{\mathrm{a}}$ & $-0.15^{\mathrm{b}}$ & $-0.09^{\mathrm{b}}$ & $-1.50^{\mathrm{a}}$ & $-1.68^{\mathrm{a}}$ & $-1.55^{\mathrm{a}}$ & $-0.83^{*}$ & $-1.19^{*}$ \\
\hline
\end{tabular}

The various superscripts indicate significant differences in the post-hoc Duncan test $(p<0.05)$.

${ }^{*} t$-test with significant different means $(p<0.05)$.

Table 2

Perception of traceability in the meat chain related to consumer segments, average scores on a 7-point scale $(n=158$ in 2001 and $n=150$ in 2004$)$

\begin{tabular}{|c|c|c|c|c|c|c|c|c|c|}
\hline \multirow[t]{2}{*}{ Statement } & \multicolumn{2}{|c|}{ Enthusiasts } & \multicolumn{2}{|c|}{ Cautious } & \multicolumn{2}{|c|}{ Pessimists } & \multirow{2}{*}{$\frac{\text { Greens }}{2004}$} & \multicolumn{2}{|l|}{ Total } \\
\hline & 2001 & 2004 & 2001 & 2004 & 2001 & 2004 & & 2001 & 2004 \\
\hline \multicolumn{10}{|l|}{ Process attributes } \\
\hline I can check the animal production method & $4.22^{\mathrm{a}}$ & $4.63^{\mathrm{a}}$ & $4.35^{\mathrm{a}}$ & $4.14^{\mathrm{b}}$ & $5.00^{\mathrm{b}}$ & $5.08^{\mathrm{c}}$ & $5.03^{\mathrm{c}}$ & 4.49 & 4.66 \\
\hline I can check the origin of the product (region, farmer and slaughterhouse) & $4.31^{\mathrm{a}}$ & $4.96^{\mathrm{a}}$ & $4.44^{\mathrm{ab}}$ & $4.33^{\mathrm{a}}$ & $4.98^{\mathrm{b}}$ & $4.84^{\mathrm{a}}$ & $4.58^{\mathrm{a}}$ & 4.55 & 4.73 \\
\hline I can check the meat packaging date & 5.53 & $5.49^{\mathrm{a}}$ & 5.47 & $5.19^{\mathrm{b}}$ & 5.84 & $5.96^{\mathrm{a}}$ & $5.77^{\mathrm{a}}$ & 5.59 & 5.57 \\
\hline I have access to information regarding the health record of the animal & $3.95^{\mathrm{a}}$ & $4.71^{\mathrm{a}}$ & $4.14^{\mathrm{a}}$ & $4.65^{\mathrm{a}}$ & $4.81^{\mathrm{b}}$ & $5.16^{\mathrm{b}}$ & $4.90^{\mathrm{ab}}$ & $4.27^{*}$ & $4.81^{*}$ \\
\hline $\begin{array}{l}\text { Organisations responsible for monitoring public health can intervene } \\
\text { in the event of a problem in the meat chain (e.g. dioxin scare: only } \\
\text { contaminated products are removed from the shelves, not all products) }\end{array}$ & 5.73 & 5.94 & 5.62 & 6.12 & 5.82 & 6.00 & 5.90 & 5.71 & 5.99 \\
\hline $\begin{array}{l}\text { In the case of abuses, individuals responsible can be clearly identified } \\
\text { and held accountable }\end{array}$ & 5.83 & 5.90 & 5.86 & 5.74 & 6.11 & 5.58 & 5.71 & 5.92 & 5.77 \\
\hline $\begin{array}{l}\text { The meat chain (from animal feed to the consumer's plate) can be } \\
\text { organised more efficiently to further reduce costs }\end{array}$ & 5.20 & 5.24 & 4.83 & 4.98 & 5.24 & 4.71 & 4.71 & 5.06 & 4.97 \\
\hline
\end{tabular}

The various superscripts indicate significant differences in the post-hoc Duncan test $(p<0.10)$.

${ }^{*} t$-test with significant different means $(p<0.05)$.

Table 3

Consumer segments and perception of the need for traceability according to meat types, average scores on a 7-point scale $(n=158$ in 2001 and $n=150$ in 2004)

\begin{tabular}{|c|c|c|c|c|c|c|c|c|c|}
\hline \multirow[t]{2}{*}{ Attribute } & \multicolumn{2}{|c|}{ Enthusiasts } & \multicolumn{2}{|c|}{ Cautious } & \multicolumn{2}{|c|}{ Pessimists } & \multirow{2}{*}{$\frac{\text { Greens }}{2004}$} & \multicolumn{2}{|l|}{ Total } \\
\hline & 2001 & 2004 & 2001 & 2004 & 2001 & 2004 & & 2001 & 2004 \\
\hline$\overline{\text { Beef }}$ & $5.02^{\mathrm{a}}$ & $4.65^{\mathrm{a}}$ & $5.14^{\mathrm{a}}$ & $4.53^{\mathrm{a}}$ & $5.89^{\mathrm{b}}$ & $5.45^{\mathrm{b}}$ & $4.79^{\mathrm{a}}$ & $5.31^{*}$ & $4.80^{*}$ \\
\hline Pork & $4.75^{\mathrm{a}}$ & $4.75^{\mathrm{a}}$ & $5.17^{\mathrm{ab}}$ & $4.60^{\mathrm{b}}$ & $5.59^{\mathrm{b}}$ & $5.33^{\mathrm{c}}$ & $4.67^{\mathrm{b}}$ & 5.16 & 4.81 \\
\hline Poultry & $4.88^{\mathrm{a}}$ & $4.96^{\mathrm{a}}$ & $5.35^{\mathrm{ab}}$ & $4.74^{\mathrm{a}}$ & $5.50^{\mathrm{b}}$ & $5.21^{\mathrm{b}}$ & $5.28^{\mathrm{b}}$ & 5.25 & 5.02 \\
\hline Meat mixtures & $5.25^{\mathrm{a}}$ & $5.04^{\mathrm{a}}$ & $5.55^{\mathrm{ab}}$ & $5.05^{\mathrm{a}}$ & $5.86^{\mathrm{b}}$ & $5.46^{\mathrm{b}}$ & $4.93^{\mathrm{a}}$ & $5.55^{*}$ & $5.11^{*}$ \\
\hline
\end{tabular}

The various superscripts indicate significant differences in the post-hoc Duncan test $(p<0.05)$

${ }^{*} t$-test with significant different means $(p<0.05)$.

the introduction of traceability systems. The scores for all meat types are still higher than the middle scale position, but show a clear decline in 2004 compared to 2001.

\section{Consumer interest in traceability information on meat labels}

\subsection{Use and importance of meat label information cues}

From the 10 meat label information cues included in the November 2005 survey, the most important and most used ones are expiry date, meat type, weight and price. For these cues, a quite consistent picture between claimed importance and claimed use is obtained (Fig. 3), i.e. claimed use levels match relatively well with claimed importance levels. The other meat label cues are evaluated as significantly less important and much lower use levels are reported, particularly so for slaughter date, nutritional value, origin and brand. These findings are consistent with previous meat consumer studies in the sense that readily interpretable search information cues, such as expiry date and meat type, rank higher in terms of importance and 


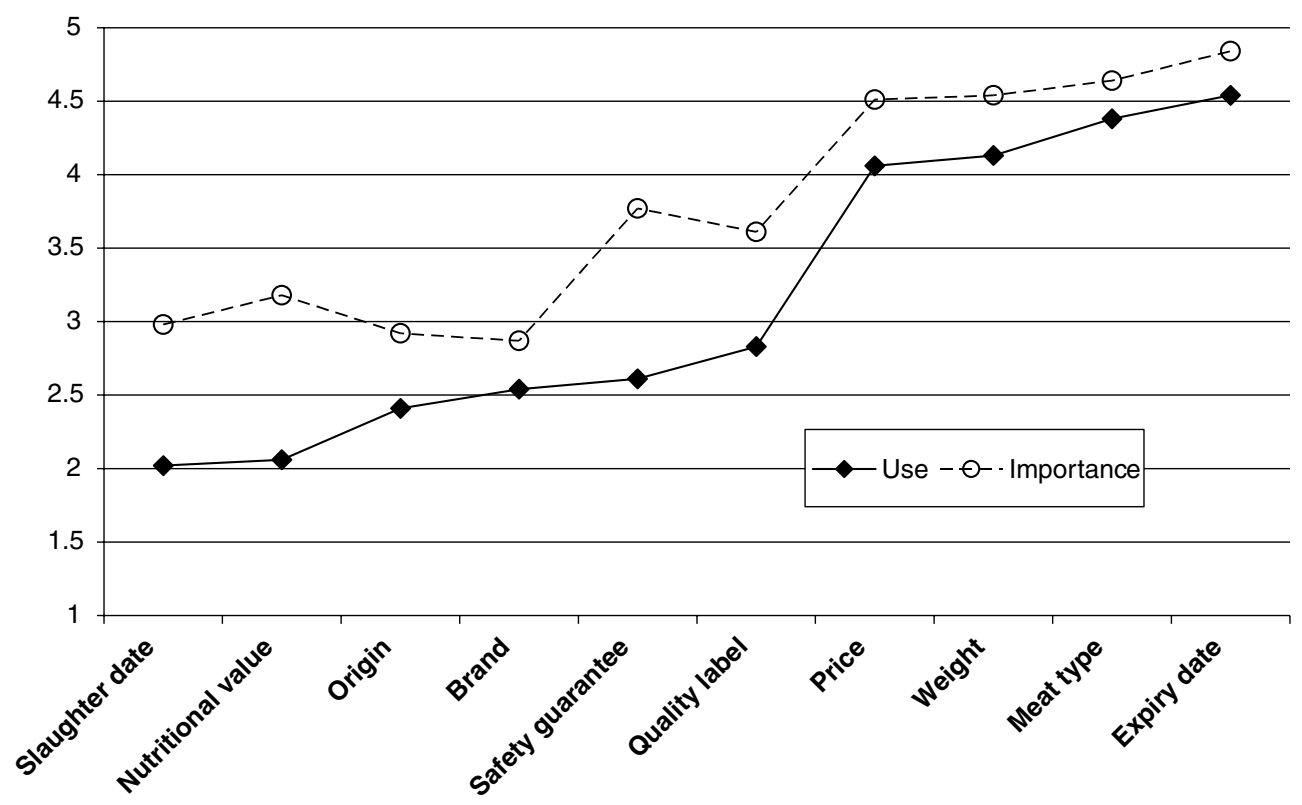

Fig. 3. Claimed importance and use of information cues on meat labels, mean scores on 5-point scales $(n=127) ; 2005$.

use as compared to credence information cues, such as origin (Verbeke \& Ward, 2006; Verbeke, Ward, \& Avermaete, 2002).

\subsection{Awareness about traceability}

With respect to awareness or subjective knowledge about traceability, about half of the respondents indicated they had a poor knowledge, i.e. $15 \%$ claimed to have never heard of traceability and 35\% indicated not really knowing what traceability is about (Fig. 4). Claimed awareness of traceability was significantly associated with education, though not with gender and age. Lower educated constituted nearly two thirds of those who claimed to have never heard about traceability, while higher educated accounted for $70 \%$ of those who reported to know traceability well or very well. Claimed awareness of traceability was not correlated with claimed importance or claimed use for any of the aforementioned information cues on meat labels.

\subsection{Who should store traceability information?}

Respondents reported a strong preference for traceability information to be collected and kept by others, rather than having to face this responsibility themselves: $69.1 \%$ of the respondents indicated that they prefer retailers or butchers to store all necessary information and to be able to make it available only upon request (Fig. 5). About

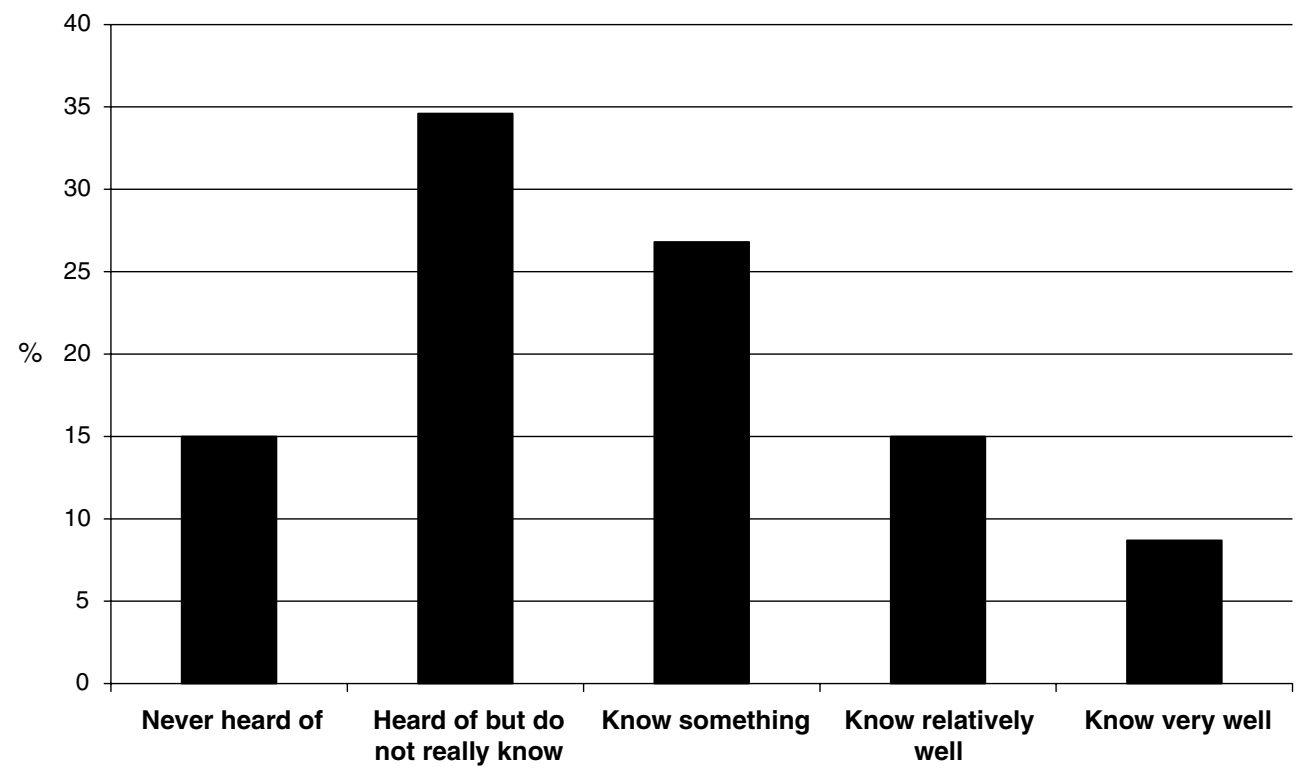

Fig. 4. Awareness of meat traceability, frequency distribution, $\%(n=127) ; 2005$. 


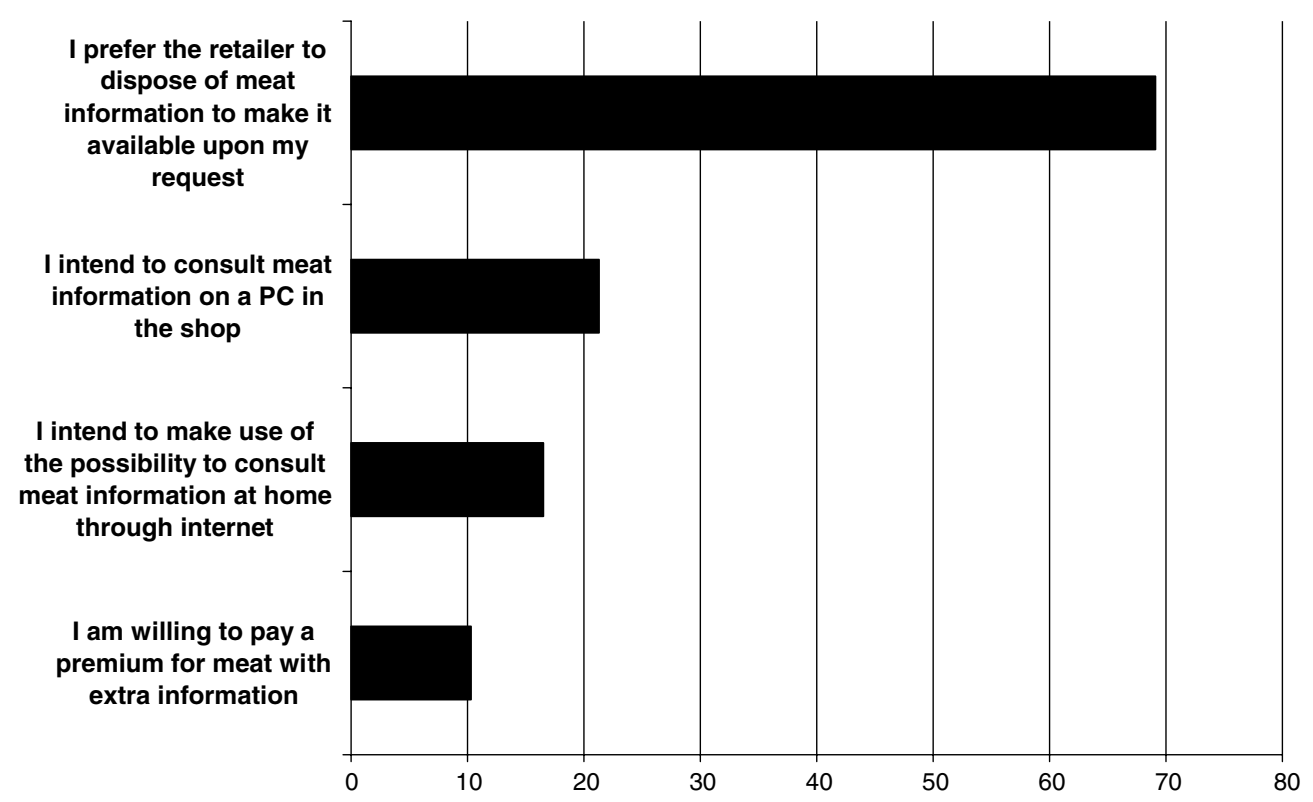

Fig. 5. Intention to consult meat information from different sources; and willingness to pay for extra information, $\%$ agree and totally agree from 5 -point scale $(n=127) ; 2005$.

one-fifth of the respondents indicated that they would be willing to consult meat information on a personal computer in the shop; about $16 \%$ would be willing to do so at home through the internet. Finally, no more than $10 \%$ indicated willingness to pay a price premium for meat with extra information.

This picture is also confirmed in Fig. 6. Mean importance scores of having personal access to different levels of origin information are below or at the mid-point of the 5-point scale. The strongest interest for the self pertains to country of origin, but note that this information cue ranked among the lower end in terms of use and importance as compared to other information cues (see Fig. 3). In contrast, respondents attached relatively high importance to the fact that retailers and government should have access to detailed origin information. Note in particular

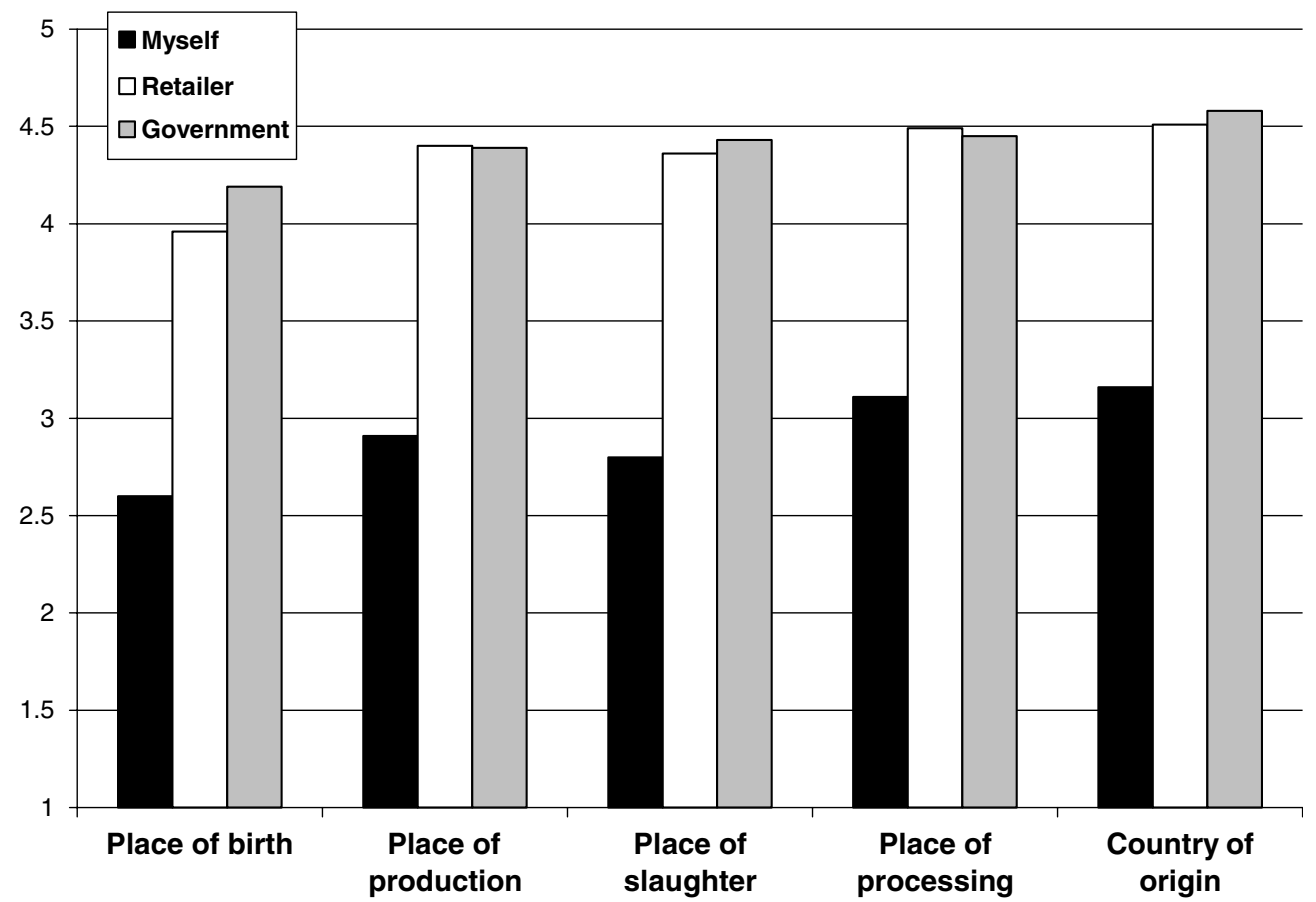

Fig. 6. Consumers' perceived importance of having access to traceability information; self versus retailer and government, mean score on 5-point importance scale $(n=127) ; 2005$. 
Table 4

Description of manipulated traceability information on meat labels

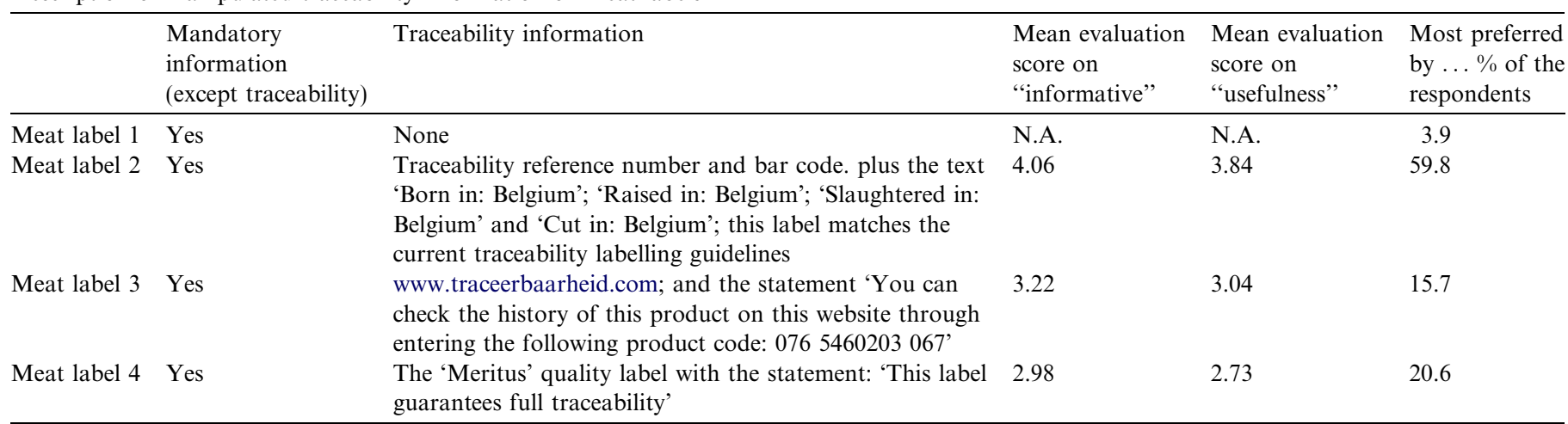

Mean evaluation scores and ranking $(n=127) ; 2005$.

that respondents made no distinction between responsibilities of retailers versus government.

\subsection{Providing traceability information through meat labels}

Respondents distinguished strongly between meat labels on which traceability information was manipulated (Table 4). When being confronted with different degrees of traceability information on labels, respondents largely rejected the meat label without specific traceability information. The most preferred label was the one with origin information, which is also reflected in its highest evaluation score on being informative and useful. This label fits with the current meat labelling practices. Note though that the fact that origin was specified as 'Belgium' may partly account for the high preference. Despite lower evaluation scores on being informative and useful, the 'Meritus' quality label $^{4}$ (presented as an alternative to specific traceability information) was preferred by more respondents (about one-fifth) as compared to the better evaluated label with website and traceability code (preferred by $15.7 \%$ ).

The label with a website address and product traceability code was significantly better evaluated on being informative by respondents with (claimed) awareness of traceability $(M=3.42$ versus $M=3.02$ for unaware respondents; $t=-1.96 ; p=0.05$ ). Finally, label preference was significantly associated with education $\left(\chi^{2}=6.54\right.$; $p=0.038$ ). One-third of the lower educated respondents reported to prefer the 'Meritus' quality label, as compared to only $13 \%$ among the higher educated. The label with a website address and traceability reference code was preferred by nearly one fifth of the higher educated versus by only $13.2 \%$ of the lower educated. No other differences in preference relating to demographics were detected.

\footnotetext{
${ }^{4}$ Meritus is a Belgian beef quality label established in 1997 as an initiative of different stakeholders in the beef chain. The label guarantees superior beef quality and safety based among others on specific conditions related to breed, slaughter age, animal welfare, good manufacturing practices in animal feed and safety controls at different levels of the beef chain. Meritus' production share is around $20 \%$ today versus $11 \%$ in 1998 and $13 \%$ in 2000 (see Fig. 7).
}

\section{Quality assurance schemes}

Developing quality assurance schemes and related labels is another way to inform consumers about the quality properties of food. Well-known examples in the EU are the French 'label rouge', the Dutch 'IKB-label', the German 'Gütesiegel' and the Belgian 'Meritus'. The increasing consumer demand for higher-quality foods led to regulations on labelling as a means to shape consumer's knowledge and behaviour, and manufacturers' product offerings and marketing practices (Caswell \& Mojduszka, 1996). Quality labelling is often related to food safety, but includes more than that. Food quality deals with a range of intrinsic and extrinsic attributes, which contribute to perceived quality by consumers (Luning \& Marcelis, 2005). Quality labelling is a way to add value to the food product (Van Trijp \& Steenkamp, 2005), serving as a tool for marketing, and holding benefits for both industry and the consumer (Verbeke \& Viaene, 1999).

Despite this increased introduction of such quality labels, several studies argue that these labels do not function as quality cues at all (Alvensleben von \& Gertken,

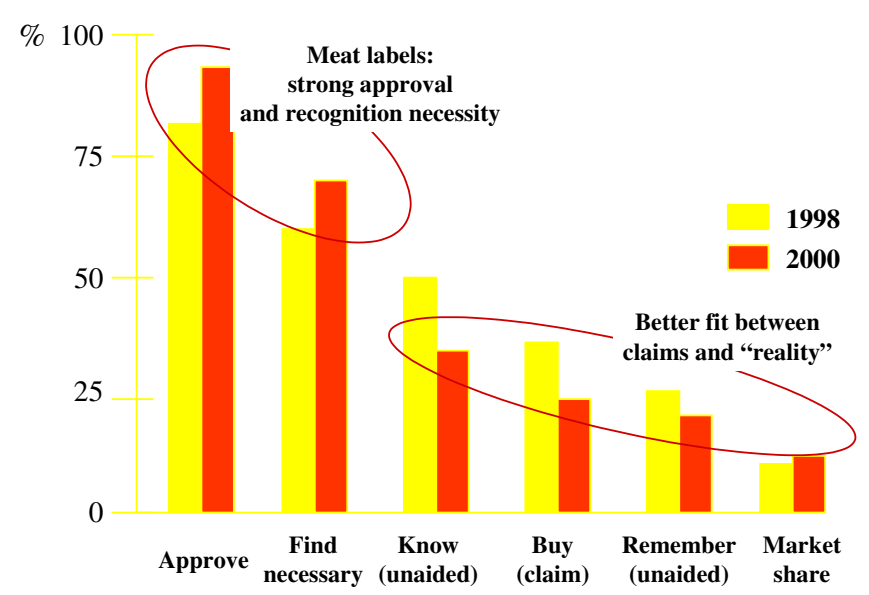

Fig. 7. Perception of meat quality labels and actual reported market share. 
1993; Grunert, 2005; Van Trijp \& Steenkamp, 2005) and consequently hardly add trust. Fig. 7 illustrates the limited knowledge and market share of meat quality labels.

A repeated consumer survey conducted in 1998 and 2000 illustrates that consumers highly approve meat labels and recognise their necessity. However, knowledge, claimed and overt behaviour are limited. Consequently, one can wonder whether the introduction of these 'voluntary' quality assurance schemes highly supported by retailers is motivated by the search for procurement management efficiency rather than by food safety and public health concerns. Concentration in the retail sector continues to increase and necessitates more suppliers to obtain the volumes for supplying the totality of the outlets. When suppliers present their products, the procurement manager has two main criteria to evaluate the products, namely the quality and the price. The most difficult to evaluate is the quality of the product since all suppliers argue that their product differs in quality from that of competitors. When a retailer manages to eliminate the discussion about quality and imposes the required quality attributes through quality assurance schemes, the job of the procurement manager becomes significantly simplified. Procurement management becomes limited to evaluating prices and verifying whether or not the specifications of the quality assurance scheme are respected. This could be the main reason explaining the success of quality assurance schemes. Other reasons relate to overall food safety concerns and the avoidance of product recall.

\section{Conclusions and future research agenda}

Despite being based on a relatively small and convenience sample - which prevents generalisation to the broader population - the empirical research into the potential of traceability information provision and quality labelling reveals some interesting issues.

First, with respect to traceability characteristics, consumers manage to distinguish between functional and process attributes. The former refer to the intrinsic opportunities of the systems, i.e. the ability to organise the chain more efficiently, monitor the chain, and assess individual responsibilities. These attributes can be regarded as the minimum requirements of a true 'traceability system'. Process attributes refer to characteristics of the production process at different levels of the chain, i.e. they can be regarded as resulting from extensions from the minimum requirements.

Second, compared to 2001, overall meat quality perception scores are higher in 2004. This should be linked with the increased efforts related to quality assurance by both the private sector and public authorities. In 2004, the cluster analysis yielded a cluster, namely the greens, additional to the three-cluster solutions (segments denoted enthusiasts, cautious and pessimists) found in 2001. None of the clusters can be typified through socio-demographic characteristics, which implies that these rather classic consumer characteristics do not allow to further define the identified clusters or market segments. Our empirical findings contribute to the debate about who is responsible, and to what extent, for providing meat quality and safety. Since functional attributes are broadly supported by all consumer groups, public policy plays an important role in guiding and monitoring this aspect of traceability. Extensions with respect to process attributes, such as production methods, are less relevant to the broad public and only interest specific market segments. Government intervention or regulation on the process attribute side of traceability is thus less evident. These attributes are more appropriate for private and voluntary initiatives of chain participants. Hence, this analysis shows that collecting market information (about consumer interest in traceability in this case) reveals differences between consumers. These differences include opportunities for the meat chains to become more market oriented, i.e. to differentiate through the development of traceability based on process attributes. Such a market oriented approach should further enable companies to counterbalance increasing quality costs, create competitive advantage and consequently obtain better profitability in today's global markets.

Third, the introduction of traceability is regarded by consumers as the most urgent in the case of meat mixtures. However, organising traceability for mixtures in terms of functional attributes is the most difficult, because different meat types can be an ingredient in one and the same product. Despite the fact that the pessimists consume meat least frequently, they regard the introduction of traceability in the meat chain as the most urgent, which indicates that traceability could be an answer to their concerns.

Future research could focus on pessimists' willingness to pay for traceability systems or additional traceability information, which are extended with process attributes on the one hand, and on a more precise characterisation of this market segment (e.g. purchase outlet, moment of meat consumption) on the other. At the level of the meat chain, it could be interesting to quantify costs and benefits for all participants in the meat chain. Another future research topic could be the distribution of these costs and benefits among chain participants, as well as the role of the retail industry as potential chain leader/gatekeeper.

Fourth, consumers clearly differentiate between information cues with respect to importance and usefulness; they appear much keener on using search quality cues than credence quality cues when making meat purchasing decisions. This finding is in line with previous studies that reported that consumers are more open to using readily interpretable and familiar quality cues (e.g. Grunert, 2005). Specific traceability information ranks low in terms of perceived importance and usefulness, which corresponds with Hobbs et al. (2005) and Verbeke and Ward (2006).

Fifth, from selected means of presenting traceability information on meat labels, a simple indication of origin 
appears most useful and preferred by consumers. Apparently, this kind of information is considered an easier heuristic or decision rule to form quality expectations, as compared a quality label or to more detailed information that could be accessed through the internet. The latter would require active information search, which was yet proven to stand a limited chance of adherence by consumers, even in situations of uncertainty (McCluskey \& Swinnen, 2004; Verbeke, 2005). Note though that this kind of indication will rank below familiar and mandatory information cues, such as end-by date and price, most likely even in trade-offs that consumers may be enforced to make (e.g. between price and other attributes).

Sixth, consumers express a strong preference that other stakeholders in the chain, more specifically retailers and government, possess traceability information, rather than facing the responsibility of collecting, processing and using this information themselves. Overall, the findings are indicative that a simple reference to origin may be the optimum solution when aiming at informing consumers about meat traceability.

Finally, the role of quality assurance schemes is debatable. Future research could focus on its real interest, more specifically in relation to procurement management at retail level. Consequently, its relationship with the development of monopolistic market power could be examined.

\section{References}

Alvensleben von, R., \& Gertken, D. (1993). Regionale Gütezeichen als Marketinginstrument bei Nahrungsmitteln. Agrarwirtschaft, 42, 247-251.

Berg, L. (2004). Trust in food in the age of mad cow disease: a comparative study of consumers' evaluation of food safety in Belgium, Britain and Norway. Appetite, 42, 21-32.

Bernués, A., Olaizola, A., \& Corcoran, K. (2003). Labelling information demanded by European consumers and relationships with purchasing motives, quality and safety of meat. Meat Science, 65, 1095-1106.

Böcker, A., \& Hanf, C.-H. (2000). Confidence lost and - partially regained: consumer response to food scares. Journal of Economic Behaviour and Organization, 43, 471-485.

Caswell, J. A., \& Mojduszka, E. M. (1996). Using informational labelling to influence the market for quality food products. American Journal of Agricultural Economics, 78, 1248-1253.

Fischer, C., Gonzalez, M., Henchion, M., \& Leat, P. (2006). Factors influencing trust-supporting mechanisms in European agri-food chains. In Proceedings of the 99th European seminar of the EAAE on 'Trust and risk in business networks' (pp. 63-72). Bonn, Germany: University of Bonn.

Frewer, L., Fischer, A., Scholderer, J., \& Verbeke, W. (2005). Food safety and consumer behaviour. In W. M. F. Jongen \& M. T. G. Meulenberg (Eds.), Innovation in agri-food systems, product quality and consumer acceptance (pp. 125-145). Wageningen: Wageningen Academic Publishers.

Gellynck, X., \& Verbeke, W. (2001). Consumer perception of traceability in the meat chain. Agrarwirtschaft, 50, 368-374.

Gellynck, X., Verbeke, W., \& Viaene, J. (2004). Quality management in the food supply chain: how does the food industry interact with consumers, retailers and public authorities? In G. Schiefer \& U. Rickert (Eds.). Quality assurance, risk management and environmental control in agriculture and food supply networks (Vol. B, pp. 443-452). Germany: Universität Bonn-ILB.
Gellynck, X., Januszewska, R., Verbeke, W., \& Viaene, J. (2005). Consumer attitudes towards food traceability and costs for the food business. In: A. Blogowski, L. Lagrange, \& E. Valceschini, E. (Eds.). In the name of quality: What kind of quality for which kind of demand(s)? Colloque International SFER (pp. 223-234). Enita Clermont Ferrand, Unité de Recherche Typicité des Produits Alimentaires.

Grunert, K. G. (2005). Food quality and safety: consumer perception and demand. European Review of Agricultural Economics, 32, 369-391.

Hobbs, J., Bailey, D., Dickinson, D., \& Haghiri, M. (2005). Traceability in the Canadian red meat sector: do consumers care? Canadian Journal of Agricultural Economics, 53, 47-65.

Jacoby, K., Chestnut, R. W., \& Silberman, W. (1977). Consumer use and comprehension of nutrition information. Journal of Consumer Research, 4, 119-128.

Knight, A., \& Warland, R. (2005). Determinants of food safety risks: a multi-disciplinary approach. Rural Sociology, 70, 253-275.

Kola, J., \& Latvala, T. (2003). Impact of information on the demand for credence characteristics. In: Proceedings 13th annual world food and agribusiness forum and symposium (IAMA) (pp. 1-10). Cancun, Mexico.

Latouche, K., Rainelli, P., \& Vermersch, D. (1998). Food safety issues and the BSE scare: some lessons from the French case. Food Policy, 23, 347-356.

Leat, P., Marr, P., \& Ritchie, C. (1998). Quality assurance and traceability - the Scottish agri-food industry's quest for competitive advantage. Supply Chain Management, 3, 115-117.

Luhmann, N. (1988). Familiarity, confidence, trust: problems and alternative. In D. G. Gambetta (Ed.), Trust (pp. 94-107). New York: Basil Blackwell.

Luning, P., \& Marcelis, W. (2005). Food quality management and innovation. In W. M. F. Jongen \& M. T. G. Meulenberg (Eds.), Innovation in agri-food systems (pp. 293-341). Wageningen: Wageningen Academic Publishers.

Malhotra, N. (1999). Marketing research: an applied orientation. third ed. Englewood-Cliffs: Prentice-Hall International Editions.

McCluskey, J. J., \& Swinnen, J. F. M. (2004). Political economy of the media and consumer perceptions of biotechnology. American Journal of Agricultural Economics, 86, 1230-1237.

Miles, S., \& Frewer, L. J. (2001). Investigating specific concerns about different food hazards. Food Quality and Preference, 12, 47-61.

Röhr, A., Lüddecke, K., Drusch, S., Müller, M. J., \& Alvensleben, R. V. (2005). Food quality and safety-consumer perception and public health concern. Food Control, 16, 649-655.

Rosa, F., Sanchez, M., \& Barrena, R. (2006). Confidence in consumerretailer relations and quality label as a compensation of the inefficiency of beef meat markets: a compared analysis among Canada, Italy and Spain. In Proceedings 99th European Seminar of the EAAE on 'Trust and risk in business networks' (pp. 235-250). Germany: Bonn University.

Salaün, Y., \& Flores, K. (2001). Information quality: meeting the needs of the consumer. International Journal of Information Management, 21, 21-37.

Schwägele, F. (2005). Traceability from an European perspective. Meat Science, 71, 164-173.

Teisl, M. F., \& Roe, B. (1998). The economics of labelling: an overview of issues for health and environmental disclosure. Agricultural and Resource Economics Review, 27, 140-149.

Theuvsen, L. (2003). Motivational limits to tracking and tracing: principal-agent problems in meat production and processing. In G. Schiefer \& U. Rickert (Eds.). Quality assurance, risk management and environmental control in agriculture and food supply networks (Vol. B, pp. 223-230). Germany: Universität Bonn-ILB.

Van Trijp, H. C. M., \& Steenkamp, J. B. E. M. (2005). Consumer-oriented new product development: principles and practice. In W. M. F. Jongen \& M. T. G. Meulenberg (Eds.), Innovation in agri-Food Systems (pp. 87-124). Wageningen Academic Publishers.

Verbeke, W. (2005). Agriculture and the food industry in the information age. European Review of Agricultural Economics, 32, 347-368. 
Verbeke, W. (2001). Beliefs, attitude and behaviour towards fresh meat revisited after the Belgian dioxin crisis. Food Quality and Preference, 12, 489-498.

Verbeke, W., \& Ward, R. (2006). Consumer interest in information cues denoting quality and origin: an application of ordered probit models to beef labels. Food Quality and Preference, 17, 453-467.

Verbeke, W., \& Vackier, I. (2004). Profile and effects of consumer involvement in fresh meat. Meat Science, 67, 159-168.
Verbeke, W., \& Viaene, J. (1999). Consumer attitude to beef quality labeling and associations with beef quality labels. Journal of International Food and Agribusiness Marketing, 10(3), 45-65.

Verbeke, W., Ward, R., \& Avermaete, T. (2002). Evaluation of publicity measures relating to the EU beef labelling system in Belgium. Food Policy, 27, 339-353.

Yee, W. M. S., Yeung, R. M. W., \& Morris, J. (2005). Food safety: building consumer trust in livestock farmers for potential purchase behaviour. British Food Journal, 107, 841-854. 